\title{
Furan in Thermally Processed Foods - A Review
}

\author{
Yun-Jeong Seok', Jae-Young Her', Yong-Gun Kim ${ }^{1}$, Min Yeop Kim ', Soo Young Jeong', \\ Mina K. Kim', Jee-yeon Lee ${ }^{2}$, Cho-il Kim ${ }^{3}$, Hae-Jung Yoon ${ }^{4}$ and Kwang-Geun Lee' \\ 'Department of Food Science and Biotechnology, Dongguk University, Goyang-si, Korea \\ ${ }^{2}$ Nutrition Policy \& Promotion Team, Korea Health Industry Development Institute, Chungcheongbuk-do, Korea \\ ${ }^{3}$ Bureau of Health Industry Promotion, Korea Health Industry Development Institute, Chungcheongbuk-do, Korea \\ ${ }^{4}$ Department of Food Safety Evaluation, National Institute of Food and Drug Safety Evaluation, \\ Ministry of Food and Drug Safety, Chungcheongbuk-do, Korea
}

(Received August 14, 2015; Revised September 14, 2015; Accepted September 21, 2015)

\begin{abstract}
Furan $\left(\mathrm{C}_{4} \mathrm{H}_{4} \mathrm{O}\right)$ is a volatile compound formed mostly during the thermal processing of foods. The toxicity of furan has been well documented previously, and it was classified as "possible human carcinogen (Group 2B)" by the International Agency for Research on Cancer. Various pathways have been reported for the formation of furan, that is, thermal degradation and/or thermal rearrangement of carbohydrates in the presence of amino acids, thermal degradation of certain amino acids, including aspartic acid, threonine, $\alpha$-alanine, serine, and cysteine, oxidation of ascorbic acid at higher temperatures, and oxidation of polyunsaturated fatty acids and carotenoids. Owing to the complexity of the formation mechanism, a vast number of studies have been published on monitoring furan in commercial food products and on the potential strategies for reducing furan. Thus, we present a comprehensive review on the current status of commercial food monitoring databases and the possible furan reduction methods. Additionally, we review analytical methods for furan detection and the toxicity of furan.
\end{abstract}

Key words: Furan, Monitoring, Reduction, Thermally processed foods

\section{INTRODUCTION}

Furan $\left(\mathrm{C}_{4} \mathrm{H}_{4} \mathrm{O}\right)$ is a colorless, heterocyclic compound with high volatility (boiling point: $31^{\circ} \mathrm{C}$ ), consisting of a five-membered aromatic ring with four carbon atoms and one oxygen atom. It has been reported that thermal processing is a main cause of furan formation. Thermal processing such as cooking, roasting, baking, pasteurization, and sterilization $(1,2)$ is involved in many food preparing processes, from the home kitchen to industrial food processing facilities, and it ensures the microbiological safety of the food for preservation and maintains particular sensory features (3). One of the known reactions during thermal processing is the Maillard reaction. This is a non-enzymatic browning

Correspondence to: Kwang-Geun Lee, Department of Food Science and Biotechnology, Dongguk University, 32, Dongguk-ro, Ilsandong-gu, Goyang-si, Gyeonggi-do 410-820, Korea E-mail: kwglee@dongguk.edu

This is an Open-Access article distributed under the terms of the Creative Commons Attribution Non-Commercial License (http:// creativecommons.org/licenses/by-nc/3.0) which permits unrestricted non-commercial use, distribution, and reproduction in any medium, provided the original work is properly cited. reaction, which involves the reaction of amino acids, peptides, and proteins with reducing sugars and vitamin C (4). Some studies have reported that furan formation occurs to a large extent during the Maillard reaction. This review presents the current status of commercial food monitoring databases and possible methods applied by various agencies for reducing furan formation in food.

Various pathways involved in furan formation. There are multiple pathways underlying furan formation, such as (i) thermal degradation or rearrangement of carbohydrates alone or in the presence of amino acids, (ii) thermal degradation of certain amino acids, (iii) oxidation of ascorbic acid under high temperatures, and (iv) oxidation of polyunsaturated fatty acids and carotenoids. The potential pathways of furan formation have been illustrated in a previously published paper (5).

Thermal degradation or rearrangement of carbohydrates: Thermal degradation and rearrangement of carbohydrates is observed in the Maillard reaction or non-enzymatic browning reactions during food processing and cooking. Even in simple component mixtures, large numbers of furan compounds are formed. Carbohydrate degra- 
dation can be divided into four pathways that lead to the formation of aldotetrose derivatives. After the final cyclization of aldotetrose, toxic furan can be generated. Reducing hexoses typically go through the Maillard reaction in the presence of amino acids and produce reactive intermediates such as 1-deoxy- and 3-deoxyosones, aldotetrose, and 2deoxy-3-keto-aldotetrose, as was demonstrated previously (4). 1-Deoxyosone undergoes $\alpha$-dicarbonyl cleavage to form aldotetrose. Aldotetrose is a compound derived from retro-aldol cleavage in the absence of amino acids, and it is known to form a limited quantity of furan. After a dehydration reaction, the formation of 2-deoxy-3-keto-aldotetrose follows retro-aldol cleavage. Consequently, 3-deoxyosone undergoes $\alpha$-dicarbonyl cleavage, followed by oxidation and decarboxylation to form 2-deoxyaldotetrose. All the aldotetrose derivatives can easily be converted into furan (4). Another study reported the precursors of furan, such as aldotetrose and 2-deoxy-aldotetrose (6). A further study, using labeling, described that furan formation originates from the aldotetrose intermediate (7). Pentose sugars (e.g., ribose) are known to form furan intermediates in the presence of amino acids, as these are converted into their 3deoxyosone derivatives. Each derivative completes a reaction with amino acids or undergoes dehydration at the C-3 hydroxyl group. The resulting intermediate can undergo $\alpha-$ dicarbonyl cleavage to produce 2-deoxyaldotetrose, which is a direct precursor of furan (2). Locas reported that pentose acts in a manner similar to hexose and is converted into its 3-deoxyosone derivative after an amino acid reaction or elimination of the C-3 hydroxyl group (4). The intermediate formed in this manner can undergo R-dicarbonyl cleavage to form 2-deoxyaldotetrose, from which furan can be produced directly (4). The formation of furan from the thermal degradation of carbohydrates is very complex, and the pathway involves mainly the Maillard reaction.

Thermal degradation of amino acids: The mechanism underlying furan formation from amino acids has been reported in a carbon-13 labeling study, which stated that amino acids that can form acetaldehyde and glycolaldehyde are able to produce furan by aldol condensation and cyclization (4). Formation of furan from thermal degradation of amino acids depends greatly on the type of amino acids involved in the process. Some amino acids such as serine and cysteine can be shunted into two pathways to produce glycolaldehyde through the Strecker reaction or to produce acetaldehyde through decarboxylation, with the loss of one ammonia molecule (8). Therefore, the amino acids stated above do not require sugar or other sources of glycolaldehyde to form furan. Both of these amino acids can be metabolized to acetaldehyde and glycolaldehyde by aldol condensation to produce aldotetrose derivatives, which are then cyclized to form furan. Several amino acids require sugar to produce furan; these include aspartic acid, threonine, and $\alpha$-alanine. These amino acids can produce only acetaldehyde (Strecker aldehyde), which implies that they require the presence of reducing sugars, serine, or cysteine to produce the glycolaldehyde that is formed during Strecker degradation (9).

Oxidation of ascorbic acid: According to recent studies, ascorbic acid is a precursor of furan (4). Ascorbic acid is known to behave in the same manner as reducing sugars, and is decomposed by two parallel mechanisms (10). Ascorbic acid is quickly oxidized into dehydro-ascorbic acid under acidic and aerobic conditions. Then, it is hydrolyzed to 2,3-diketogulonic acid (DKG) by ring cleavage with the addition of water. This DKG can be decarboxylized to form xylosone (4) and 2-deoxyaldotetrose, which is used in furan formation. On the other hand, dehydro-ascorbic acid cannot be formed under anaerobic conditions (4). Under non-oxidative pyrolytic conditions, ascorbic acid cannot be oxidized to form DKG. Hence, it can be hydrolyzed and undergoes $\beta$-elimination, followed by decarboxylation to form 3-deoxypentosulose (DP), which can then be processed in the ribose pathway to produce furan. Under heating and in the absence of water, furan formation is avoided because dehydro-ascorbic acid can be cyclized and exists mainly in its hemiketal form (4). Ascorbic acid forms furan substitutes on heating at $300^{\circ} \mathrm{C}$ in the absence of water. The compounds that are primarily produced under these conditions are furfural and furoic acid (9). Under acidic aerobic conditions, ascorbic acid can be oxidized to dehydro-ascorbic acid and is then hydrolyzed to DKG by ring cleavage with the addition of water. Decarboxylated DKG then forms xylosone, which is ultimately dehydrated to 3-hydroxy-2-pyrone and 2-furoic acid or 3-deoxypentosulose, and ultimately forms furfural. Ascorbic acid can form 2-deoxyaldotetrose, from which furan is finally generated (4). Ascorbic acid is one of the compounds that affects the browning reaction of orange juice, along with 3hydroxy-2-pyrone, 5-hydroxymethylfurfural (HMF), furfural, 5-hydroxymaltol, and 2-furoic acid (11). A study of orange juice and a juice model system confirmed that ascorbic acid produces furan precursors such as furfural and 2furoic acid, which react with sugars or chelating agents (9).

Under anaerobic conditions, however, the formation of dehydro-ascorbic acid is less likely to occur, because ascorbic acid undergoes hydrolysis under anaerobic conditions, followed by $\beta$-elimination and decarboxylation, which leads to the formation of 3-deoxypentosulose, the intermediate of 2-deoxyaldotetrose. Furfural can also be produced from ascorbic acid under both aerobic and anaerobic conditions (4).

Oxidation of polyunsaturated fatty acids and carotenoids: In general, oxidative degradation of polyunsaturated fatty acids (PUFAs) and the ensuing formation of lipid peroxides are undesirable reactions in food processing because lipid peroxides can cause a disagreeable, rancid, off flavor in food, and some lipid peroxides are known to be 
carcinogenic to humans (4). In a combinatory reaction with oxygen species and/or an enzymatic reaction by lipoxygenases, lipid hydroperoxides can be produced from PUFAs. At the intermediate stage of these reactions, 2-alkenals, 4-oxo2-alkenals, and 4-hydroxy-2-alkenals can be produced. Among these intermediates, 4-hydroxy-2-alkenals can act as precursors for furan as demonstrated previously (4). Similarly, 5-pentylfuran could be produced from 4-hydroxy-2butenal through cyclization. Ironically, this process alters the 4-hydroxy-2-alkenals into less toxic furan derivatives with high volatility. Xu reported that transition of metal ions catalyzes homolytic cleavage of PUFA hydroperoxides to form 2-alkenals, 4-oxo-2-alkenals, and 4-hydroxy-2-alkenals (12). Sayre reported that 5-pentylfuran was related to formation of 4-hydroxy-2-nonenal (4-HNE) when the furan is formed from ethanolic 4-HNE solutions under acidic conditions (8). Vichi reported the proportional relation between 5-pentylfuran concentrations and the level of olive oil oxidation (13).

Some model systems showed that monounsaturated acid (oleic acid) did not form furan. Linoleic acid heated for $30 \mathrm{~min}$ at $118^{\circ} \mathrm{C}$ in water formed $125 \mathrm{ng} / \mathrm{g}$ furan and linolenic acid formed $625 \mathrm{ng} / \mathrm{g}$ furan (14). It has previously been reported that furan is produced from linolenic acid at lower temperatures $\left(110 \sim 220^{\circ} \mathrm{C}\right)$ than that reported for furan formation from ascorbic acid or the Maillard reaction (13).

Analytical methods for furan detection. The FDA reported the first method for furan detection and quantification in foods (15). This method involves the preparation of samples under cold conditions and headspace sampling incubation at $80^{\circ} \mathrm{C}$. Porous layer open tubular (PLOT) columns are used for chromatographic separation with mass spectrometric detection in selected ion monitoring (SIM) mode. The column, with bonded polystyrene-divinylbenzene, can separate small volatile molecules well. Quantification was based on a standard addition method and used a deuterated furan internal standard ( $\mathrm{d}_{4}$-furan).

Headspace analysis: Separation of furan from the food sample into the headspace vial varies depending on time, temperature, and the liquidity of the sample. Effective separation is only possible with the appropriate equilibration time, and/or efficient agitation by the addition of magnetic bars to the headspace vial (16). An appropriate amount of water must be present or added to ensure that the sample is entirely fluid before analysis. Typical headspace procedures involve heating the sample to ensure volatilization of the analyte into the headspace. However, furan does not require excessive heating; in fact, this is inadvisable and unnecessary because of its highly volatile nature (17). Some papers have reported increases in the headspace incubation temperature from $30^{\circ} \mathrm{C}$ to $50^{\circ} \mathrm{C}$. This led to an increase of only $50 \%$ in the furan peak area. Addition of salt is much more effective in increasing the sensitivity of detection of the furan signal (18). Based on many studies, a consensus has been reached that an incubation temperature of $50^{\circ} \mathrm{C}$ or below is appropriate, as this provides the proper sensitivity for detection $(10,18)$. It is necessary to confirm that furan is formed at the selected incubation temperature in each study prior to sample analysis (17).

Headspace sampling by solid phase microextraction (SPME): It is now advised that SPME be implemented for effective furan analysis (19). The SPME method focuses on an SPME needle that is coated with a polymeric material. The SPME needle is first exposed to the headspace of the vial that contains the analytes to absorb volatile compounds for $10 \sim 60 \mathrm{~min}$, and these are then desorbed thermally for $15 \mathrm{~min}$ at $90 \sim 300^{\circ} \mathrm{C}$ in the injection port of the GC to send the volatiles into the GC column. On the other hand, in direct headspace analysis, the headspace gas is taken from the vial and injected directly into a gas chromatographymass spectrometry (GC-MS) system. SPME allows sample concentration and is more sensitive. The limits of detection for furan are low (16).

Several parameters, including the fiber type, extraction (exposure) time/temperature, and the saturation of the aqueous phase in the headspace vial, affect optimal SPME conditions. Some studies focused on the selection of optimal fibers for the analysis of furan. They report that the best option for the analysis of furan is a carboxen/polydimethylsiloxane (CAR/PDMS) fiber, as it shows marked advantages such as selectivity; the next best options were the divinylbenzene/carboxen/polydimethylsiloxane (DVB/CAR/ PDMS), polydimethylsiloxane/divinylbenzene (PDMS/DVB), polyacrylate, and carbowax/divinylbenzene (CW/DVB) fibers (3). The fiber should be baked at $300^{\circ} \mathrm{C}$ for an hour before the analysis of furan. Several studies have also reported on optimization of the fiber exposure temperature and time for furan analysis $(16,17,20)$. These studies showed that the exposure temperature should be $50^{\circ} \mathrm{C}$ or below, to discourage the formation of additional furan, which can increase the sensitivity of the system. Exposure time did not have a marked effect on the formation of additional furan, and 20 min of exposure was typically chosen (17). The optimal SPME conditions for furan analysis thus involve equilibration for $20 \mathrm{~min}$ at $50^{\circ} \mathrm{C}$. Different SPME fibers have been compared, and the CAR/PDMS was selected for furan analysis because of its high sensitivity.

A previous study also investigated the SPME conditions for furan analysis (17), and reported on optimal sample preparation and equilibration temperature and time. Three approaches to sample preparation, depending on sample states, were reported. The amounts of furan for analysis were $1 \mathrm{~g}$ for solid samples and $5 \mathrm{~g}$ for liquid and paste samples, as the latter samples contained low levels of furan. The optimal SPME fiber exposure temperature among the various temperatures tested, viz., $30^{\circ} \mathrm{C}, 40^{\circ} \mathrm{C}, 50^{\circ} \mathrm{C}, 60^{\circ} \mathrm{C}$, $70^{\circ} \mathrm{C}$, and $80^{\circ} \mathrm{C}$, was $50^{\circ} \mathrm{C}$. Furan production increased with 
higher temperatures because furan was being formed during the equilibration step, in addition to the furan already present in samples (10). An exposure time of 20 min was selected, as exposure time did not markedly affect furan formation, thus confirming the findings of the previous study (21).

Identification and quantification of furan using GCMS: There are several ways to identify furan using GCMS, such as evaluating the GC retention time (e.g., $\pm 2 \%$ of the standards), or the ratio of the quantification ion of furan at $\mathrm{m} / \mathrm{z} 68$ compared to the qualification ion at $\mathrm{m} / \mathrm{z} 39$ and again compared to the ratio with standards (e.g., agreement to $\pm 25 \%$ ). Quantification methods use various standards, such as external calibration graphs, or internal calibration graphs using $\mathrm{d}_{4}$-furan as a deuterium-labeled internal standard. High amounts of internal standard must be avoided to prevent an allocation to the $\mathrm{m} / \mathrm{z} 68$, which is the signal for quantification of the furan ion from the fragment ion of [M$\mathrm{d} 2]^{+}$. HP-PLOT Q columns showed relatively high sensitivity and worked well with the selected CAR/PDMS fiber (10).

Toxicology of furan. The presence of furan in commercial food products is of great concern to many public health agencies such as the US Food and Drug Administration (FDA) and European Food Safety Authority (EFSA) and has prompted research into and identification of risks conferred by furan by many international organizations, including the National Toxicology Program (NTP) and International Agency for Research on Cancer (IARC). The toxicity of furan is well documented from animal studies, and a summary of the classified furan risks can be found in Table 1.

Oral toxicity and carcinogenicity: In rats, furan is bioactivated to its reactive intermediate due to the high activity of CYP2E1, and reaches the liver, which is the main target organ of furan toxicity $(22,23)$. Male F344 rats given a single dose of $30 \mathrm{mg} / \mathrm{kg}$ body weight of furan by oral gavage developed hepatocellular necrosis, inflammation, and elevated liver enzyme activities in the serum within $24 \mathrm{hr}$ of furan administration, followed by regenerative cell proliferation for $48 \mathrm{hr}$, and demonstrated residual inflammation after 8 days. Approximating a single dose, exposure of Sprague-Dawley rats to furan at $40 \mathrm{mg} / \mathrm{kg}$ body weight for up to 14 days resulted in a significant decrease in body weight, with increased relative liver weights, and significant increases in serum transaminases, alkaline phosphatase, cholesterol, triglycerides, and total bilirubin (22). To determine furan toxicity in the low-dose range, which more closely approximates potential human exposures, several researchers have recently investigated macroscopic and histological changes in livers of male and female F344 rats after 90 days of oral treatment with various furan doses, i.e., $0.0,0.03,0.12,0.5,2.0$, and $8.0 \mathrm{mg} / \mathrm{kg}$ body weight (22). Gross morphological alterations, characterized by nodular structures, were seen in the livers of all animals in the highdose group, with the caudate and left lateral lobe being affected most markedly (23). Given the results of this study, $0.03 \mathrm{mg} / \mathrm{kg}$ body weight was announced as a NOAEL for furan hepatotoxicity in rats.

Genotoxicity: Genotoxicity of furan has also been reported in many studies. Furan appears to be mutagenic to mouse lymphoma cells, independent of S9 activation. High doses of furan caused structural chromosome abnormalities, but did not affect chromatid exchange in mouse bone marrow cells. With a single oral dose of 200 or $100 \mathrm{mg} / \mathrm{kg}$ body weight, furan did not cause uncontrolled DNA synthesis in mouse or rat hepatocytes in vivo (5). Mutagens such as cis-2-butene-1,4-dial are similar to unsaturated compounds that react with DNA. This was directly mutagenic at non-toxic concentrations in a Salmonella enterica Typhimurium strain (TA104) that was sensitive to aldehydes, but not to some other strains (4). It is possible that furan or cis2-butene-1,4-dial reacts with DNA in target cells and can play a major role in furan-induced tumors. After bioactivation into its metabolites, furan induces loss of ATP, which causes an inevitable uncoupling of hepatic mitochondrial oxidative phosphorylation. This would activate cytotoxic enzymes, including endonucleases that produce DNA double-strand cleavage, leading to cell death (4). Based on these findings of previous studies, furan is considered a genotoxic compound.

Furan monitoring databases. In 2004, the U.S. FDA analyzed the level of furan in commercial canned and jarred foods, the production of which typically involves harsh thermal processing followed by sealing and packaging. Since then, the techniques for analyzing furan in food products have improved greatly, allowing better detection of furan. Greater public concern about the risks of furan in common food products has led to the investigation of the raw materials used for the production of all commercial food products. Hence, many international agencies such as the EFSA, FDA, and Food Standards Agency (FSA), and countries such as Korea, Taiwan, China, and Chile have

Table 1. The classification of furan risks

\begin{tabular}{lll}
\hline \hline Organization & Class & \\
\hline IARC & 2B & Possibly carcinogenic to humans \\
NTP & $\mathrm{R}$ & Reasonably anticipated to be human carcinogen \\
EU & $\mathrm{C} 2$ & Substances which should be regarded carcinogenic to humans \\
\hline
\end{tabular}


Table 2. The detected levels of furan as analyzed by EFSA in 2004 (24)

\begin{tabular}{lcc}
\hline \hline Product category & Number of samples & Furan (ng/g) \\
\hline Coffee instant & 109 & 394 \\
Coffee, roasted bean & 30 & 3660 \\
Coffee, roasted ground & 110 & 1936 \\
Coffee, not specified & 596 & 2016 \\
Coffee brew & 89 & $42-45$ \\
Baby food & 1617 & $31-32$ \\
Infant formula & 11 & $0.2-3.2$ \\
Baked beans & 57 & $22-24$ \\
Beer & 102 & $3.3-5.2$ \\
Cereal product & 190 & $15-18$ \\
Fish & 47 & 17 \\
Fruit juice & 250 & $2.2-4.6$ \\
Fruits & 142 & $2-6.4$ \\
Meat products & 174 & $13-17$ \\
Milk products & 64 & $5-5.6$ \\
Sauces & 271 & $8.3-11$ \\
Soups & 270 & $23-24$ \\
Soy sauce & 94 & 27 \\
Vegetable juice & 80 & $2.9-9$ \\
Vegetables & 192 & $6.9-9.6$ \\
Cocoa & 14 & $9-10$ \\
Snacks and crisps & 133 & $9.6-10$ \\
Soft drinks & 18 & $0.8-1.2$ \\
Soya products & 15 & 6.7 \\
Sweets & 61 & $5-6$ \\
Tea & 22 & $1-1.7$ \\
Vegetable fats & 13 & $1.5-1.7$ \\
Wine and liquors & 20 & 1.3 \\
\hline
\end{tabular}

been monitoring furan in food products and have constructed databases for estimation of exposure.

In Europe, the EFSA collects data on furan concentrations in heat-treated commercial food products to better estimate dietary exposure since 2004 and present exposure estimates for different populations annually. Their database contains 5,050 analytical results for furan levels in food from 20 countries in Europe. As shown in Table 2, the highest furan levels were detected in coffee, with mean values between 42 and 3,660 ng/g for brewed coffee and roasted coffee beans. Furan was detected at levels between 0.2 and $3.2 \mathrm{ng} / \mathrm{g}$ in infant formula, and ranged from 22 to $24 \mathrm{ng} / \mathrm{g}$ in baked beans, from 13 to $17 \mathrm{ng} / \mathrm{g}$ in meat products, and from 23 to $24 \mathrm{ng} / \mathrm{g}$ in soups. In soy sauce, furan was detected at $27 \mathrm{ng} / \mathrm{g}$, which forms during thermal processing. In vegetable and vegetable juice, furan levels ranged between 6.9 and $9.6 \mathrm{ng} / \mathrm{g}$, and 2.9 and $9 \mathrm{ng} / \mathrm{g}$, respectively. Mean furan exposure was estimated to range between 0.03 and $0.59 \mathrm{ng} / \mathrm{g}$ body weight per day for adults and between 0.09 and $0.22 \mathrm{ng} / \mathrm{g}$ body weight per day for infants (24). A major contributor to furan exposure for adults was brewed coffee, accounting on average for $85 \%$ of total furan exposure. Major contributors to furan exposure in toddlers and other children were fruit juice, dairy products, and cereal-based products, while jarred baby food was another major contributor to furan exposure in toddlers.

In the US, the FDA also collected data on the monitoring of furan in various commercial food products publically available since 2004. Subsequently, the FDA also issued an

Table 3. Furan contents as analyzed by the FDA in 2008 (15)

\begin{tabular}{|c|c|c|}
\hline Product category & Product & Furan (ng/g) \\
\hline \multirow{13}{*}{ Baked Goods } & Archway Ginger Snaps & 5.6 \\
\hline & "JIFFY" Corn Muffin Mix & ND \\
\hline & Bagel Nation Plain Bagels (toasted) & ND \\
\hline & Biscuit Shack Restaurant Biscuits & ND \\
\hline & Bodacious Bagels Plain Bagels (Toasted) & ND \\
\hline & Bodacious Bagels Whole Wheat Bagels (Toasted) & ND \\
\hline & Dunkin’ Donuts French Cruller Doughnuts & 3.6 \\
\hline & Nabisco Fig Newtons & 1.7 \\
\hline & Nabisco Lorna Doone Shortbread Cookies & 3.6 \\
\hline & Newman’s Own Organics Fig Newmans & 12.5 \\
\hline & TOPS Ginger Snaps & 30.1 \\
\hline & Whole Foods Blueberry Muffins & ND \\
\hline & Whole Foods Morning Glory Muffins & ND \\
\hline \multirow{9}{*}{ Beverages } & Celestial Seasonings $100 \%$ Green Tea Bags & 0.4 \\
\hline & Dominick’s 100\% Orange Juice (Canned) & 1.4 \\
\hline & Gold Peak Tea Lemon Iced Tea & 0.8 \\
\hline & Lipton Summer Peach Ice Tea Mix & ND \\
\hline & Lipton Unsweetened PureLeaf Iced Tea & 0.4 \\
\hline & Mountain Dew Live Wire & 1 \\
\hline & Nestea Unsweetened Ice Tea Mix & ND \\
\hline & Safeway Green Tea $100 \%$ Natural Tea & 0.5 \\
\hline & Sunkist Orange Soda & 0.4 \\
\hline
\end{tabular}


Table 3. Continued

\begin{tabular}{|c|c|c|}
\hline Product category & Product & Furan $(\mathrm{ng} / \mathrm{g})$ \\
\hline \multirow{12}{*}{ Breakfast Cereals } & B\&G Cream of Wheat Enriched Farina & ND \\
\hline & Food Lion Raisin Bran & 13.8 \\
\hline & Great Value Oven-Toasted Old Fashioned Oats & ND \\
\hline & Harris Teeter Bran Flakes & 16.1 \\
\hline & Harris Teeter Frosted FruitO's & 6.1 \\
\hline & Heartland Granola Cereal & ND \\
\hline & Kellogg's All-Bran Complete Wheat Flakes & 25.4 \\
\hline & Kellogg's Fruit Loops & 15 \\
\hline & Nabisco Cream of Wheat & ND \\
\hline & Post Grape-Nuts & 11.6 \\
\hline & Post Raisin Bran & 15 \\
\hline & Post Shredded Wheat & 2.3 \\
\hline \multirow{7}{*}{ Infant Foods } & Beech-Nut Mixed Cereal For Baby & 3.9 \\
\hline & Earth's Best Organic Whole Grain Rice Cereal & ND \\
\hline & Gerber Graduates Biter Biscuits & 6.4 \\
\hline & Gerber Prunes With Apples & 10.1 \\
\hline & Gerber Single Grain Barley Cereal For Baby & ND \\
\hline & Gerber Single Grain Rice Cereal For Baby & ND \\
\hline & O Organics For Baby Organic Prunes & 11.6 \\
\hline \multirow{2}{*}{ Meats } & IHOP Sausage Links & ND \\
\hline & Waffle House Sausage Patties & ND \\
\hline \multirow{5}{*}{ Mixtures } & Flavorite Worcestershire Sauce & 14.1 \\
\hline & French's Worcestershire Sauce & 14.9 \\
\hline & Hunt's Bold Barbecue Sauce & 15.5 \\
\hline & Kraft Honey Hickory Smoke Barbecue Sauce & 13.5 \\
\hline & Open Pit Original Barbecue Sauce & 28 \\
\hline \multirow{14}{*}{ Snacks } & Alpine Valley Butter Flavor Popcorn & 28.5 \\
\hline & Anderson's Frozen Custard Curly Que Fries & ND \\
\hline & Arby’s Curly Fries & ND \\
\hline & Bachman Thin'n Right Baked Pretzels & 62.8 \\
\hline & Cape Cod Old Fashioned Kettle Cooked Potato Chips & 3.5 \\
\hline & Doritos Nacho Cheese Flavored Tortilla Chips & 12 \\
\hline & McDonald's French Fries & ND \\
\hline & Rold Gold Classic Style Sticks Pretzels & 40.1 \\
\hline & Ruffles Original Baked! Potato Crisps & 21.7 \\
\hline & TOPS Festingos Round Bite Size $100 \%$ White Corn Tortilla Chips & 5.8 \\
\hline & TOPS Pretzelwerks Snaps Pretzels & 37.9 \\
\hline & Tostitos $100 \%$ White Corn Crispy Rounds & 6.2 \\
\hline & Troyer Farms Potato Chips & 7.3 \\
\hline & Troyer Farms Premium Popcorn with White Cheddar Cheese & 30 \\
\hline
\end{tabular}

action plan for furan monitoring in 2005, which involved expanding the furan databases to about 600 food samples, cooperating with the Alcohol and Tobacco Tax and Trade Bureau to accumulate data on furan levels in alcoholic beverages, and conducting exposure assessments on furan. Since then, the studies have been processed and posted for public awareness. Table 3 shows the results of furan detected in commercial food commodities in 2008. In the category of baked goods, furan was not detected in most of the samples tested, except for ginger snaps $(5.6 \mathrm{ng} / \mathrm{g})$, doughnuts $(3.6$ $\mathrm{ng} / \mathrm{g}$ ), and cookies (3.6 ng/g). In the beverage category, several products contained a low level of furan, but all were below $1.4 \mathrm{ng} / \mathrm{g}$. Among the category of breakfast cereals, furan was detected at its highest in all-bran wheat flakes, at a level of $25.4 \mathrm{ng} / \mathrm{g}$. Infant foods contained furan at levels ranging from not-detectable to $11.6 \mathrm{ng} / \mathrm{g}$. Furan was not detected in all meat/processed meat products tested. Among the sauce categories, the levels of furan ranged from 13.5 $\mathrm{ng} / \mathrm{g}$ to $28 \mathrm{ng} / \mathrm{g}$. The highest furan level in this report was in the snacks category, with $62.8 \mathrm{ng} / \mathrm{g}$ furan being present in pretzel snacks (15).

The FSA also monitored a range of retail foodstuffs from England, from 2011 to 2013, as shown in Table 4. The significance of the data monitoring system in England is that it 
Table 4. Furan contents as analyzed by the FSA in 2014 (25)

\begin{tabular}{|c|c|c|c|}
\hline Sampling date & Product & Number of samples & Furan $(\mathrm{ng} / \mathrm{g})$ \\
\hline 2012 & Breakfast Cereals & 22 & 51 \\
\hline 2013 & & 22 & 41 \\
\hline 2012 & Biscuits \& crackers & 20 & 45 \\
\hline 2013 & & 20 & 39 \\
\hline \multirow[t]{8}{*}{2012} & Coffee / coffee substitutes & 20 & 1533 \\
\hline & Coffee / coffee substitutes, as consumed & 20 & 47 \\
\hline & Roast & 8 & 3412 \\
\hline & Roast, as consumed & 8 & 116 \\
\hline & Instant & 6 & 457 \\
\hline & Instant, as consumed & 6 & 2 \\
\hline & Other & 6 & 103 \\
\hline & Other, as consumed & 6 & 0.07 \\
\hline \multirow[t]{8}{*}{2013} & Coffee / coffee substitutes & 20 & 1554 \\
\hline & Coffee / coffee substitutes, as consumed & 20 & 43 \\
\hline & Roast & 8 & 3368 \\
\hline & Roast, as consumed & 8 & 104 \\
\hline & Instant & 6 & 589 \\
\hline & Instant, as consumed & 6 & 4 \\
\hline & Other & 6 & 100 \\
\hline & Other, as consumed & 6 & 1 \\
\hline 2012 & Baby Food excluding processed cereal & 20 & 48 \\
\hline 2013 & & 20 & 39 \\
\hline 2012 & Vegetable crisps & 4 & 17 \\
\hline 2013 & & 4 & 15 \\
\hline 2012 & Popcorn & 2 & 78 \\
\hline 2013 & & 2 & 91 \\
\hline 2012 & Tortilla / corn snacks & 2 & 15 \\
\hline 2013 & & 2 & 17 \\
\hline 2012 & Cereal bars / granola & 4 & 7 \\
\hline 2013 & & 4 & 4 \\
\hline 2012 & Prefab snacks & 4 & 24 \\
\hline 2013 & & 4 & 23 \\
\hline 2012 & Novelty gingerbread & 4 & 0.07 \\
\hline 2013 & & 4 & 5 \\
\hline 2012 & Cocoa / Choc powder & 3 & 20 \\
\hline 2013 & & 3 & 12 \\
\hline 2012 & Prunes (canned) & 2 & 39 \\
\hline 2013 & & 2 & 30 \\
\hline 2012 & Olives (canned) & 2 & 8 \\
\hline 2013 & & 2 & 8 \\
\hline 2012 & Jams / preserves & 4 & 2 \\
\hline 2013 & & 4 & 3 \\
\hline
\end{tabular}

allows the direct comparison of detected furan levels in the same sample category in each year. In the UK, furan was detected at 1533 to $1554 \mathrm{ng} / \mathrm{g}$ in coffee, and at 39 to $48 \mathrm{ng} / \mathrm{g}$ in baby foods. Over the course of a year, the detected levels of furan in many food commodities, including breakfast cereal and crackers decreased, except for the furan levels in popcorn which increased (from 78 in 2012 to $91 \mathrm{ng} / \mathrm{g}$ in 2013). The furan levels in breakfast cereal decreased from 51 to $41 \mathrm{ng} / \mathrm{g}$; in biscuits and crackers, it decreased from 45 to $39 \mathrm{ng} / \mathrm{g}$; in baby food, excluding processed cereal, it decreased from 48 to $39 \mathrm{ng} / \mathrm{g}$; in vegetable crisps, it decreased from 17 to $15 \mathrm{ng} / \mathrm{g}$; in cocoa, it decreased from 20 to $12 \mathrm{ng} /$ 
$\mathrm{g}$; and in prunes (canned), it decreased from 39 to $30 \mathrm{ng} / \mathrm{g}$ (25).

In Korea, levels of furan in commercial heat-processed foods have been monitored by use of optimized furan analysis conditions, using SPME-GC/MS, since 2010 (17). The results obtained on the analysis of various commercial

Table 5. Furan levels as analyzed in Korea (17)

\begin{tabular}{|c|c|c|c|c|c|}
\hline Product category & Package type & Product & Furan (ng/g) & Range (ng/g) & Number of samples \\
\hline \multirow[t]{9}{*}{ Vegetables } & \multirow[t]{6}{*}{ Canned } & Sweet corn & 9.44 & $5.05-17.45$ & 4 \\
\hline & & Kidney bean & 45.60 & $43.60-47.45$ & 1 \\
\hline & & Bamboo shoot & 3.29 & $3.08-3.58$ & 1 \\
\hline & & Mushroom & 29.04 & $25.56-30.92$ & 1 \\
\hline & & Sesame leaf & 53.64 & $47.36-58.30$ & 2 \\
\hline & & Baby corn & 5.66 & $5.57-5.76$ & 1 \\
\hline & \multirow[t]{3}{*}{ Jarred } & Olive & 3.29 & $1.33-6.26$ & 6 \\
\hline & & Cucumber pickle & 3.99 & $2.29-5.80$ & 2 \\
\hline & & Caper & 2.94 & $2.55-3.93$ & 2 \\
\hline \multirow[t]{3}{*}{ Meats } & \multirow[t]{3}{*}{ Canned } & Pork luncheon meat & 7.42 & $2.84-15.39$ & 6 \\
\hline & & Korean seasoned pork or beef & 85.72 & $14.21-193.95$ & 3 \\
\hline & & Chicken & 19.94 & $18.54-21.96$ & 1 \\
\hline \multirow[t]{7}{*}{ Juice } & \multirow[t]{7}{*}{ Canned } & Grape & 4.96 & $2.62-9.19$ & 3 \\
\hline & & Orange & 4.59 & $3.33-7.59$ & 4 \\
\hline & & Pomegranate & 2.68 & $2.65-2.74$ & 1 \\
\hline & & Mango & 3.78 & $3.67-3.84$ & 1 \\
\hline & & Apple & 5.24 & $5.06-5.40$ & 1 \\
\hline & & Grape & 3.18 & $2.62-4.12$ & 3 \\
\hline & & Orange & 3.45 & $3.24-3.60$ & 2 \\
\hline \multirow[t]{10}{*}{ Baby foods } & \multirow[t]{10}{*}{ Jarred } & Strawberry & 2.74 & $2.20-3.53$ & 4 \\
\hline & & Grape & 2.42 & $1.92-3.02$ & 3 \\
\hline & & Blueberry & 2.32 & $2.30-2.35$ & 1 \\
\hline & & Apple & 4.75 & $4.49-4.97$ & 1 \\
\hline & & Mixed fruits & 3.10 & $2.55-3.39$ & 1 \\
\hline & & Apple & 6.19 & $6.15-6.24$ & 1 \\
\hline & & Pear & 11.63 & $10.86-12.93$ & 1 \\
\hline & & Mixed fruits & 9.45 & $9.02-9.75$ & 1 \\
\hline & & Chicken, rice & 61.94 & $58.68-65.10$ & 1 \\
\hline & & Broccoli, carrot, cheese & 33.91 & $32.65-35.60$ & 1 \\
\hline \multirow[t]{4}{*}{ Nutritional/diet drinks } & \multirow[t]{4}{*}{ Jarred } & Apple, blueberry & 3.43 & $3.39-3.50$ & 1 \\
\hline & & Apple, pear, oat, meal & 7.69 & $7.59-7.75$ & 1 \\
\hline & & Butternut squash & 47.41 & $46.15-48.96$ & 1 \\
\hline & & Peach, banana, muesli & 20.43 & $18.54-21.59$ & 1 \\
\hline \multirow[t]{5}{*}{ Soup } & \multirow[t]{5}{*}{ Canned } & Sweet potato, apple & 97.21 & $92.64-102.48$ & 1 \\
\hline & & Vitamin & 7.43 & $4.85-10.08$ & 4 \\
\hline & & Red ginseng & 7.12 & $0.77-19.57$ & 3 \\
\hline & & Dietary fibre & 7.84 & $2.39-13.68$ & 2 \\
\hline & & Royal jelly, honey & 6.02 & $3.49-7.40$ & 1 \\
\hline \multirow[t]{10}{*}{ Sauce } & \multirow[t]{10}{*}{ Jarred } & Mushroom & 16.93 & $15.48-18.41$ & 1 \\
\hline & & Potato & 32.48 & $27.22-36.20$ & 1 \\
\hline & & Chicken, noddle & 10.19 & $8.99-11.15$ & 1 \\
\hline & & Clam chowder & 14.23 & $12.40-15.51$ & 1 \\
\hline & & Bean, bacon & 18.86 & $15.72-20.68$ & 1 \\
\hline & & Chili sauce & 6.71 & $6.10-7.03$ & 1 \\
\hline & & Pork rib sauce & 12.04 & $10.26-13.68$ & 1 \\
\hline & & Pepper sauce & 12.67 & $9.54-17.82$ & 1 \\
\hline & & Oyster sauce & 38.11 & $35.19-43.82$ & 1 \\
\hline & & Spaghetti sauce & 40.57 & $37.68-45.87$ & 1 \\
\hline
\end{tabular}


canned and jarred food products consumed in Korea are summarized in Table 5. In aseptically processed and packaged food products, such as canned and jarred products, furan levels have to be estimated, as furan may be lost by evaporation. In this study, furan was detected in all food samples, and ranged from $0.77 \mathrm{ng} / \mathrm{g}$ to $193.95 \mathrm{ng} / \mathrm{g}$, with red ginseng drinks containing the lowest levels and Korean seasoned beef containing the highest levels of furan. Food

Table 6. Furan levels as analyzed in Taiwan (26)

\begin{tabular}{|c|c|c|}
\hline Product category & Product & Furan (ng/g) \\
\hline \multirow{4}{*}{ Baby foods } & $\mathrm{G}$ apple prune food & 9.9 \\
\hline & G apple jam baby food & 14.1 \\
\hline & G mixed vegetable baby food & 58.5 \\
\hline & G vegetable chicken baby food & 124.1 \\
\hline \multirow[t]{6}{*}{ Baby formulas } & $\mathrm{W}$ gold baby formula & 6.3 \\
\hline & $\mathrm{N}$ baby formula & 26.1 \\
\hline & K milk powder & 6.5 \\
\hline & $\mathrm{W}$ fruits milk powder & 13.9 \\
\hline & F high quality milk powder & 2.7 \\
\hline & $\mathrm{N}$ baby cereal powder apple-pear flavored & 28.7 \\
\hline \multirow[t]{3}{*}{ Beers } & G beer & 11.3 \\
\hline & $\mathrm{B}$ beer & 20.0 \\
\hline & $\mathrm{H}$ beer & 3.0 \\
\hline \multirow[t]{6}{*}{ Coffee } & G cafe & 150.0 \\
\hline & B coffee & 85.2 \\
\hline & $\mathrm{N}$ coffee 3 in 1 & 58.4 \\
\hline & $M$ reduced sugar low fat coffee 3 in 1 & 56.5 \\
\hline & M freeze dried coffee mix & 55.7 \\
\hline & U special blended instant coffee & 58.0 \\
\hline \multirow[t]{4}{*}{ Juices } & C $100 \%$ tomato juice & 7.0 \\
\hline & $\mathrm{C}$ asparagus drink & 4.0 \\
\hline & $P$ mixed fruit and vegetables juice drink & 33.8 \\
\hline & W's grape juice & 46.7 \\
\hline \multirow[t]{11}{*}{ Miscellaneous } & K soybean sauce & 71.2 \\
\hline & B H barbecue sauce & 21.7 \\
\hline & K salad dressing & 65.3 \\
\hline & $\mathrm{C}$ tomato ketchup & 44.2 \\
\hline & M chili sauce & 12.2 \\
\hline & B H clear chicken broth & 26.1 \\
\hline & H clear chicken broth & 37.1 \\
\hline & S clear chicken broth & 50.2 \\
\hline & $\mathrm{C}$ vegetarian vegetable & 114.2 \\
\hline & W barbecue sauce & 123.0 \\
\hline & W L fried bean sauce & 113.2 \\
\hline \multirow[t]{4}{*}{ Jams } & L strawberry jam & 15.2 \\
\hline & L grape jam & 9.2 \\
\hline & $\mathrm{G}$ peanut jam & 13.2 \\
\hline & F L fructose & 9.2 \\
\hline \multirow[t]{3}{*}{ Fish } & F tuna slice packed in water & 4.2 \\
\hline & O roasted fish & 75.2 \\
\hline & $\mathrm{R}$ mackerel in tomato sauce & 35.6 \\
\hline \multirow[t]{3}{*}{ Canned foods } & I oriental pickling melon in sauce & 30.5 \\
\hline & $\mathrm{W}$ fried gluten with peanuts in soy sauce & 99.5 \\
\hline & $\mathrm{H}$ pork taste flavored & 76.2 \\
\hline \multirow[t]{3}{*}{ Cereals } & $\mathrm{N}$ nutritious cereal drink & 24.1 \\
\hline & N koko krunch & 30.1 \\
\hline & $\mathrm{N}$ honey star & 16.8 \\
\hline
\end{tabular}


samples that are cooked with soy sauce, including canned sesame leaf and Korean seasoned beef, showed higher levels of furan than did other food samples. Some studies have reported that the furan levels in soy sauce ranged from 29 to $91 \mathrm{ng} / \mathrm{g}(10)$. Acidic, neutral, and basic volatile fragments originating from hydrolyzed soy protein can form a certain amount of furan. In addition to the acid hydrolyzed soy sauce per se, the thermal processing involved in the canning process increases the furan levels significantly to 370 $\mathrm{ng} / \mathrm{g}$ after thermal processing of soy (27). The levels of furan in the fruit juice category ranged between 1.65 and $9.19 \mathrm{ng} / \mathrm{g}$. A high level of vitamin C or ascorbic acid in fruit juice may have contributed to the formation of furan, as vitamin $\mathrm{C}$ and thermal processing are major contributors to furan formation. All jarred baby foods analyzed in this study contained furan, with levels ranging from 3.39 to $102.48 \mathrm{ng} / \mathrm{g}$. Baby foods are generally heated at high temperatures to protect against microbiological contamination, which may enhance furan formation.

Researchers in Taiwan published the furan levels of 10 categories of commercial food products, including baby foods, baby formulas, beers, coffee, juices, miscellaneous, jams, fish, canned foods, and cereals, using an advanced HS-SPME-GC-MS method, in 2010 (Table 6). The groups of food products containing high levels of furan included baby foods, coffees, sauces, and soups. The levels ranged between $0.4 \mathrm{ng} / \mathrm{g}$ (in beverages) and $150 \mathrm{ng} / \mathrm{g}$ (in coffee) (26). For baby foods, the detected furan levels ranged from $4.25 \mathrm{ng} / \mathrm{g}$ to $124.24 \mathrm{ng} / \mathrm{g}$, depending on the composition of the baby foods. Furan was also detected in infant formulas, with levels ranging from $2.4 \mathrm{ng} / \mathrm{g}$ to $28.7 \mathrm{ng} / \mathrm{g}$. The detected furan levels were higher in fruit-based food samples than in milk-based foods. Among the food groups, coffee contained the highest furan levels. It is assumed that excessively high temperature during roasting may be the major reason for the high levels of furan in coffee. A group of miscellaneous foods, including sauces, broths, and soups, was also analyzed in this study. The furan concentrations detected in these food commodities ranged from $1.5 \mathrm{ng} / \mathrm{g}$ to $123.0 \mathrm{ng} / \mathrm{g}$. The highest level of furan in this group was detected in barbecue sauce. The major component of barbecue sauce is soy sauce, which contains a relatively high level of furan.

Another study analyzed furan levels in foodstuffs in China. Frequently consumed foods in China were divided to 11 categories, including infant formula (11 samples), bread (10 samples), coffee (nine samples), fruit juice (19 samples), dairy product (15 samples), nutritional drinks (12 samples), canned jam (seven samples), flavorings (five samples), vinegars (18 samples), beers (13 samples) and soy sauce (14 samples) and analyzed. Furan was detected in all analyzed food samples at levels ranging between notdetectable in infant formula and $210.7 \mathrm{ng} / \mathrm{g}$ in soy sauce (Table 7). In coffee, furan was present at high levels, rang-
Table 7. Furan levels as analyzed in China (28)

\begin{tabular}{lrcc}
\hline \hline Product category & $\begin{array}{r}\text { Furan } \\
(\mathrm{ng} / \mathrm{g})\end{array}$ & $\begin{array}{c}\text { Range } \\
(\mathrm{ng} / \mathrm{g})\end{array}$ & $\begin{array}{c}\text { Number } \\
\text { of samples }\end{array}$ \\
\hline Infant formulas & 15.0 & $0.0 \sim 43.8$ & 11 \\
Bread & 4.0 & $0.0 \sim 10.4$ & 10 \\
Coffee & 60.6 & $13.5 \sim 150.7$ & 9 \\
Juice & 5.3 & $0.0 \sim 14.3$ & 19 \\
Milk product & 1.5 & $0.0 \sim 3.3$ & 15 \\
Nutritional drinks & 16.2 & $0.0 \sim 44.4$ & 12 \\
Jams & 30.4 & $2.1 \sim 79.4$ & 7 \\
Flavors & 9.3 & $1.9 \sim 16.8$ & 5 \\
Vinegars & 38.3 & $2.9 \sim 145.8$ & 18 \\
Beers & 4.9 & $0.0 \sim 15.2$ & 13 \\
Soy sauce & 128.8 & $51.0 \sim 224.7$ & 14 \\
\hline
\end{tabular}

ing between 13.5 and $150.7 \mathrm{ng} / \mathrm{g}$, with an average of 60.6 $\mathrm{ng} / \mathrm{g}$. These high levels were in agreement with previous studies $(9,20,27)$. However, the detected levels of furan in soy sauce was slightly higher than those reported in previous studies, with levels in China ranging from 59.5 to 210.7 $\mathrm{ng} / \mathrm{g}$, with an average of $128.8 \mathrm{ng} / \mathrm{g}$ (28). This study suggests that soybean is one of the raw materials that more easily forms furan during thermal processing, as soybean includes high levels of fat and proteins.

In a study conducted in Chile, the furan levels were monitored in 14 groups of Chilean commercial food products (5). These results are summarized in Table 8. Furan was present in most of the samples analyzed in this study. Furan levels varied considerably, depending on the food samples, and ranged from not-detectable in fried meat to high levels in crisps $(259 \mathrm{ng} / \mathrm{g})$ and coffee $(936 \mathrm{ng} / \mathrm{g})$. In the case of wheat crackers, Chilean products had a darker color than those from European countries. This color difference would explain the higher levels of furan in the Chilean product. A darker color implies that the food was exposed to thermal

Table 8. Furan levels as analyzed in Chile (5)

\begin{tabular}{lccr}
\hline \hline \multirow{2}{*}{ Product category } & \multicolumn{2}{c}{ Number of tested samples } & $\begin{array}{r}\text { Furan } \\
\text { (ng/g) }\end{array}$ \\
\cline { 2 - 3 } & Total & Positive & 4.0 \\
\hline Tomato sauce & 8 & 6 & 6.5 \\
Orange juice & 4 & 4 & 6.9 \\
Canned peaches & 2 & 2 & 8.5 \\
Jarred fruit baby food & 3 & 3 & 3.5 \\
Peas & 3 & 3 & 3.0 \\
Peach marmalade & 5 & 5 & 6.5 \\
Brewed coffee & 4 & 4 & 936.0 \\
Automatic machine coffee & 6 & 5 & 259.0 \\
Crisps & 7 & 6 & 91.0 \\
"Soda"-type crackers & 6 & 6 & 3.9 \\
Toased bread & 6 & 3 & 20.0 \\
Whole breakfast cereal & 4 & 4 & 22.2 \\
Breakfast cereal & 6 & 2 & 0 \\
Fried meat & 5 & 0 & \\
\hline
\end{tabular}


processing for a long time; therefore, more furan would be formed (5).

Considering all the data described above, the highest furan levels were detected in roasted coffee beans (average: $3660 \mathrm{ng} / \mathrm{g}$ ), followed by not-specified coffee (average: 2016 $\mathrm{ng} / \mathrm{g}$ ) and roasted ground coffee (average: $1936 \mathrm{ng} / \mathrm{g}$ ). The three highest levels were all reported by the EFSA (24). The lowest furan levels in coffee were found in brewed coffee, at $6.5 \mathrm{ng} / \mathrm{g}$ as analyzed in Chile (5). In baby foods, such as infant formula categories, furan was detected at $124.1 \mathrm{ng} / \mathrm{g}$ in vegetable/chicken baby food consumed in Taiwan (26). According to an FDA report, furan levels in all the samples ranged from not-detectable to $11.6 \mathrm{ng} / \mathrm{g}$ (15). There were remarkable differences in the results of baby food analyses across countries. It is assumed that the differences in components in baby food samples underlie these discrepancies. In Korean seasoned pork or beef, furan was detected at $85.72 \mathrm{ng} / \mathrm{g}$, which is high compared to furan levels in other meat products (17). The EFSA reported furan levels in meat products ranging from 13 to $17 \mathrm{ng} / \mathrm{g}$, whereas it was notdetectable according to the FDA report and the monitoring data analyzed in Chile.

Strategies for reducing furan levels in food products. The common strategy to reduce the toxin levels in foods includes changing the heating conditions or reducing the precursor levels (29). Reducing furan levels is challenging, as compared to reducing the levels of other contaminants. First, changing the thermal processing parameters, such as temperature and time, cannot be modified substantially, as it is required for ensuring the microbiological safety of foods. Second, furan is produced from a variety of precursors such as carbohydrates, polyunsaturated fatty acids, and ascorbic acid. Ascorbic acid is the most frequently found latent precursor of furan, followed by unsaturated fatty acids and sugars (30). With multiple pathways involved in the formation of furan, controlling this process becomes more challenging. Lastly, the high volatility of furan makes the development of a strategy for reducing furan more challenging.

Most of the furan reduction strategies to date have focused on addition of food additives and/or controlling the precursors of furan formation. To date, many previous studies had been conducted on the use of food additives. The effect of food additives on the Maillard reaction has recently been reported by using a food model system (30,31). Using model systems including glucose, alanine, and serine, the reaction of furan with $0.1 \mathrm{M}$ of various metal ions, such as iron sulfate, magnesium sulfate, calcium sulfate, and zinc sulfate, and with antioxidants, such as butyl hydroxytoluene (BHT) and butyl hydroxyanisole (BHA) and sodium sulfite, were analyzed (32). The furan levels in the glucose/ alanine model system increased with all additives, by 36 $419 \%$, except with addition of sodium sulfite. A significant decrease in furan formation was shown in the glucose/alanine model when sodium sulfite was added, while it increased by $419 \%$ in a sample to which zinc sulfate was added. In most cases, furan levels were decreased, except for samples with added zinc sulfate, in the model system containing alanine and serine, or magnesium and BHT in the model system containing serine. Reduction in furan formation occurred in the following order: sodium sulfite $>$ BHA $>$ iron sulfate $>$ BHT $>$ calcium sulfate (32). The reduction efficiency of the different food additives in a soy sauce model system has also been reported (29). Addition of calcium, magnesium sulfate, BHT, BHA, and sodium sulfite decreased the formation of furan significantly in the following order: calcium sulfate $>$ magnesium sulfate $>$ BHT $>$ BHA $>$ sodium sulfite. In comparison with these additives, other additives such as manganese sulfate, zinc sulfate, iron sulfate, and ascorbic acid, resulted in levels analogous to those in the control (no added food additives) or significantly increased the amount of furan (29).

Adding antioxidants can be an efficient way to reduce furan levels. Antioxidants potentially inhibit furan formation from thermal oxidation of PUFAs and carotenoids because they are scavengers of free radicals formed by PUFA oxidation. One study published in 2011 reported that antioxidants such as tocopherol acetate and BHA reduced furan formation from a PUFA by up to $70 \%$ (14). On the other hand, another study reported increased furan formation from a linoleic acid model system, despite the addition of BHT (31). Furthermore, the presence of metal ions in the Maillard reaction affects the rate of formation of Maillard reaction products; however, the mechanism underlying this phenomenon is not clearly established (29).

Use of precursor control has also been reported as a reduction strategy. In a model system using orange juice, development of furfural from ascorbic acid was hindered by the presence of mannitol and ethanol as free radical scavengers (9). Mitigation of atmospheric oxygen reduces furan development from some precursors, particularly ascorbic acid, as do the addition of sulfite and the autoxidation of unsaturated fatty acids (14).

\section{CONCLUSIONS}

Furan is a naturally occurring compound present in many types of foods. There are multiple pathways by which furan is formed, such as thermal degradation or rearrangement of carbohydrates alone or in the presence of amino acids, thermal degradation of some amino acids, oxidation of ascorbic acid at high temperatures, and oxidation of PUFAs and carotenoids. Owing to its high volatility, furan has been analyzed using a headspace or SPME coupled with GC-MS. Furan detectability is much more sensitive now than it was in previous years, and detection of low levels is possible because of improved techniques for furan analysis. For 
these reasons, the interest in furan risks has increased markedly worldwide. Monitoring and estimation of dietary exposure to furan has been conducted by various national agencies such as the EFSA, FDA, FSA, and by countries such as Korea, Taiwan, China, and Chile. The highest furan levels were detected in coffee categories such as roasted coffee beans, not-specified coffee, and roasted ground coffee, based on the information obtained from the monitoring databases reviewed above. Furan is inevitably absorbed by the intestine and lungs. It can pass through biological membranes and finally reaches various organs. Studies have shown that furan is carcinogenic to rats and mice, and it has been classified as being possibly carcinogenic to humans. Reduction of furan levels in foodstuffs is more challenging than reducing those of other contaminants because thermal processing such as sterilization and pasteurization, which can lead to furan formation from various precursors, is necessary to ensure the microbiological safety of foods. Moreover, given the high volatility of furan, would limit applicability evaluation. Food additives such as calcium sulfate, magnesium sulfate, BHT, BHA, and sodium sulfite have been shown to reduce furan levels in a soy sauce model system.

\section{ACKNOWLEDGMENTS}

This research was supported by a grant (13162MFDS049) from Ministry of Food and Drug Safety in 2013-2015.

\section{REFERENCES}

1. Becalski, A. and Seaman, S. (2005) Furan precursor in food: a model study and development of a simple headspace method for determination of determination furan. J. AOAC Int., 88, 102-106.

2. Crews, C. and Castle, L. (2007) A review of the occurrence, formation and analysis of furan in heat-processed foods. Trends Food Sci. Technol., 18, 365-372.

3. Hasnip, S., Crews, C. and Castle, L. (2006) Some factors affecting the formation of furan in heated foods. Food Addit. Contam., 23, 219-227.

4. Perez Locas, C. and Yaylayan, V.A. (2004) Origin and mechanistic pathways of formation of the parent furan --a food toxicant. J. Agric. Food Chem., 52, 6830-6836.

5. Mariotti, M.S., Toledo, C., Hevia, K., Gomez, J.P., Fromberg, A., Granby, K., Rosowski, J., Castillo, O. and Pedreschi, F. (2013) Are Chileans exposed to dietary furan? Food Addit. Contam. Part A, 30, 1715-1721.

6. Zoller, O., Sager, F. and Reinhard, H. (2007) Furan in food: headspace method and product survey. Food Addit. Contam., 24 Suppl 1, 91-107.

7. Maga, J.A. (1979) Furans in foods. CRC Crit. Rev. Food Sci. Nutr., 11, 355-400.

8. Sayre, L.M., Arora, P.K., Iyer, R.S. and Salomon, R.G. (1993) Pyrrole formation from 4-hydroxynonenal and primary amines. Chem. Res. Toxicol., 6, 19-22.
9. Yaylayan, V.A. (2006) Precursors, formation and determination of furan in food. J. Consum. Prot. Food Saf., 1, 5-9.

10. Mark, J., Pollien, P., Lindinger, C., Blank, I. and Märk, T. (2006) Quantitation of furan and methylfuran formed in different precursor systems by proton transfer reaction mass spectrometry. J. Agric. Food Chem., 54, 2786-2793.

11. Vranova, J. and Ciesarova, Z. (2009) Furan in food - a review. Czech J. Food Sci., 27, 1-10.

12. Xu, G. and Sayer, L.M. (1998) Structural characterization of a 4-hydroxy- 2-alkenal-derived fluorophore that contributes to lipoperoxidation- dependent protein cross-linking in aging and degenerative disease. Chem. Res. Toxicol., 11, 247-251.

13. Vichi, S., Pizzale, L., Conte, L.S., Buxaderas, S. and LópezTamames, E. (2003) Solid-phase microextraction in the analysis of virgin olive oil volatile fraction: modifications induced by oxidation and suitable markers of oxidative status. J. Agric. Food Chem., 51, 6564-6571.

14. Owczarek-Fendor, A., De Meulenaer, B., Scholl, G., Adams, A., Van Lancker, F., Eppe, G., De Pauw, E., Scippo, M.L. and De Kimpe, N. (2011) Furan formation from lipids in starchbased model systems, as influenced by interactions with antioxidants and proteins. J. Agric. Food Chem., 59, 2368-2376.

15. U.S. FDA (Food and Drug Administration). (2008) Exploratory data on furan in food: individual food products. Available from: http://www.fda.gov/Food/FoodborneIllnessContaminants/ChemicalContaminants/ucm078439.htm.

16. Goldmann, T., Périsset, A., Scanlan, F. and Stadler, R.H. (2005) Rapid determination of furan in heated foodstuffs by isotope dilution solid phase micro-extraction-gas chromatography - mass spectrometry (SPME-GC-MS). Analyst, 130, 878-883.

17. Kim, T.K., Kim, S. and Lee, K.G. (2010) Analysis of furan in heat-processed foods consumed in Korea using solid phase microextraction-gas chromatography/mass spectrometry (SPME-GC/MS). Food Chem., 123, 1328-1333.

18. Mariotti, M., Granby, K., Fromberg, A., Risum, J., Agosin, E. and Pedreschi, F. (2012) Furan occurrence in starchy food model systems processed at high temperatures: effect of ascorbic acid and heating conditions. J. Agric. Food Chem., 60, 10162-10169.

19. Stadler, R. (2006) Furan: summary of industry activities. In report of a workshop held on analytical methods and brainstorming on the elements to be included in a database. Joint DG SANCO/EFSA/DG JRC workshop, Brussels, Accessed May 19, 2006.

20. Kuballa, T., Stier, S. and Strichow, N. (2005) Furan concentrations in coffee and coffee beverages. Dtsch. Lebensm Rundsch., 101, 229-235.

21. Shinoda, Y., Murata, M., Homma, S. and Komura, H. (2004) Browning and decomposed products of model orange juice. Biosci. Biotechnol. Biochem., 68, 529-536.

22. Burka, L.T., Washburn, K.D. and Irwin, R.D. (1991) Disposition of [14C]furan in the male F344 rat. J. Toxicol. Environ. Health, 34, 245-257.

23. Gill, S., Bondy, G., Lefebvre, D.E., Becalski, A., Kavanagh, M., Hou, Y., Turcotte, A.M., Barker, M., Weld, M., Vavasour, E. and Cooke, G.M. (2010) Subchronic oral toxicity study of furan in Fischer-344 rats. Toxicol. Pathol., 38, 619-630.

24. EFSA (European Food Safty Authority). (2011) Update on 
furan levels in food from monitoring years 2004-2010 and exposure accessment. EFSA J., 9, 2347.

25. FSA (Food Standards Agency). (2014) Acrylamide and furan in a range of UK retail foodstuffs. Available from: http:// www.food.gov.uk/science/research/surveillance/food-surveys/ food-survey-information-sheets-2014/acrylamide-and-furan.

26. Liu, Y.T. and Tsai, S.W. (2010) Assessment of dietary furan exposures from heat processed foods in Taiwan. Chemosphere, 79, 54-59.

27. Senyuva, H.Z. and Gökmen, V. (2005) Analysis of furan in foods. Is headspace sampling a fit-for-purpose technique. Food Addit. Contam., 22, 1198-1202.

28. Sijia, W., Enting, W. and Yuan Y. (2014) Detection of furan levels in select Chinese foods by solid phase microextractiongas chromatography/mass spectrometry method and dietary exposure estimation of furan in the Chinese population. Food
Chem. Toxicol., 64, 34-40.

29. Kim, M.Y., Her, J.Y., Kim, M.K. and Lee, K.G. (2015) Formation and reduction of furan in a soy sauce model system. Food Chem., 189, 114-119.

30. Shinoda, Y., Komura, H., Homma, S. and Murata, M. (2005) Browning of model orange juice solution: factors affecting the formation of decomposition products. Biosci. Biotechnol. Biochem., 69, 2129-2137.

31. Ramonaityté, D.T., Keršiené, M., Adams, A., Tehrani, A.K. and Kimpe, D.N. (2009) The interaction of metal ions with Maillard reaction products in a lactose-glycine model system. Food Res. Int., 42, 331-336.

32. Kim, J.S., Her J.Y. and Lee K.G. (2015) Formation and reduction of carcinogenic furan in various model systems containing food additives. Food Chem., 189, 108-113. 